\title{
Western Indian Ocean coral communities: bleaching responses and susceptibility to extinction
}

\author{
T. R. McClanahan ${ }^{1, *}$, M. Ateweberhan ${ }^{2}$, N. A. J. Graham ${ }^{3}$, S. K. Wilson ${ }^{3,4}$, \\ C. Ruiz Sebastián ${ }^{5}$, M. M. M. Guillaume ${ }^{6,7}$, J. H. Bruggemann ${ }^{7}$ \\ ${ }^{1}$ Wildlife Conservation Society, Marine Programs, 2000 Southern Boulevard, Bronx, New York 10460-1099, USA \\ ${ }^{2}$ Coral Reef Conservation Project, PO Box 99470, Mombasa, Kenya \\ ${ }^{3}$ School of Marine Science \& Technology, University of Newcastle, Newcastle upon Tyne, NE1 7RU, UK \\ ${ }^{4}$ Australian Institute of Marine Science, TMC, Townsville, Queensland 4810, Australia \\ ${ }^{5}$ Advanced Research Center for Applied Microbiology, University of the Western Cape, Belville, South Africa \\ ${ }^{6}$ Département Milieux et Peuplements Aquatiques, UMR 5178 CNRS-UPMC-MNHN, BOME, Muséum National d'Histoire \\ Naturelle, 61 rue Buffon, 75005 Paris, France \\ ${ }^{7}$ Laboratoire d'Ecologie marine (ECOMAR), Université de la Réunion, BP 7151, 97715 Saint-Denis, La Réunion, France
}

\begin{abstract}
A field study of coral bleaching and coral communities was undertaken spanning 8 countries and $\sim 35^{\circ}$ of latitude in 2005. This was combined with studies in southern Kenya and northeast Madagascar in 1998 and Mauritius in 2004 to develop a synoptic analysis of coral community structure, bleaching response, susceptibility of the communities to bleaching, and the relative risk of extinctions in western Indian Ocean coral reefs. Cluster analysis identified 8 distinct coral communities among the 91 sites sampled, with 2 distinct communities in northern South Africa and central Mozambique, a third in the central atolls of the Maldives, and 5 less differentiated groups, in a swath from southern Kenya to Mauritius, including Tanzania, the granitic islands of the Seychelles, northeast Madagascar, and Réunion. Massive Porites, Pavona, and Pocillopora dominated the central and northern Indian Ocean sites and, from historical records, replaced dominance by Acropora and Montipora. From southern Kenya to Mauritius, coral communities were less disturbed, with Acropora and Montipora dominating, and a mix of subdominants including branching Porites, Fungia, Galaxea, massive Porites, Pocillopora, and Synarea. The survey identified an area from southernmost Kenya to Tanzania as having the least disturbed and highest diversity reefs, and as being a regional priority for management. Taxa vulnerable to future extinction based on their response to warm water, population density, and commonness include largely low-diversity genera with narrow environmental ranges, such as Gyrosmilia interrupta, Plesiastrea versipora, Plerogyra sinuosa, and Physogyra lichtensteini.
\end{abstract}

KEY WORDS: ENSO · Biodiversity · Climate change · Degree Heating Weeks · Meta-population · Monitoring · Remote sensing $\cdot$ Seawater temperature

Resale or republication not permitted without written consent of the publisher

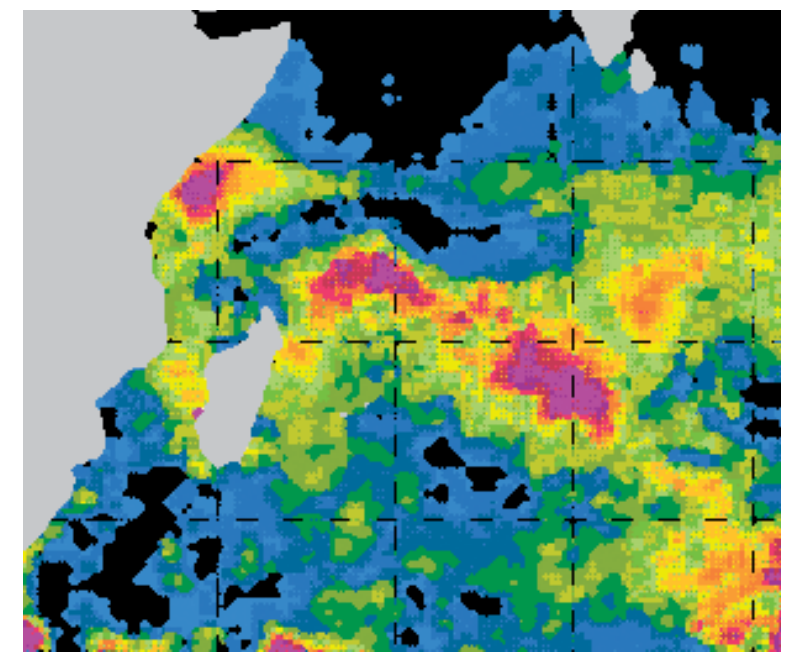

Degree Heating Weeks (DHW) in the western Indian Ocean on April 30, 1998; magenta: maximum DHW.

Data and image: NOAA/NESDIS Coral Reef Watch (http://coralreefwatch.noaa.gov/satellite)

\section{INTRODUCTION}

The western Indian Ocean experienced a rare and large-scale temperature anomaly in 1998 that produced large-scale coral bleaching and mortality (Wilkinson et al. 1999, Goreau et al. 2000). Subsequently, there have been other more spatially limited temperature anomalies and bleaching events, most notably in Mauritius in 2004 (McClanahan et 
al. 2005a) and much of the southern Indian Ocean in 2005 (McClanahan et al. 2007). The 2005 anomalies produced degree-heating weeks (DHWs) sufficient enough to predict coral bleaching (Liu et al. 2005, McClanahan et al. 2007). These warm-water events are expected to increase in coming decades and have serious implications for the persistence of corals and associated organisms (Hoegh-Guldberg 1999, Hughes et al. 2003, Sheppard 2003, Graham et al. 2006, Wilson et al. 2006). Consequently, understanding the diversity of responses of corals to bleaching, how this varies spatially and how it is affected by previous bleaching events is a key concern for coral reef ecology and management.

Despite the large spatial and taxonomic scale of most bleaching events, field studies of coral bleaching are often site- or nation- and taxon-specific and limited by the efforts of few investigators (Gleason 1993, Marshall \& Baird 2000, McClanahan et al. 2001, McClanahan et al. 2005a). This may lead to a parochial view of the bleaching effects that does not consider the larger spatial and taxonomic extent of the impact as well as the meta-population nature of coral populations (van Woesik 2000). This makes it difficult to identify regionallevel area and taxon priorities for management. The research reported here provides a broad-scale view of the response of a number of coral taxa and sites in the western Indian Ocean to the 1998 and 2005 anomalous warm-water events. Additionally, our field-sampling method allowed for a snapshot that reflects the current status of these coral communities in the context of past disturbances. We use these data to evaluate structure and diversity of the coral communities on a broad scale as well as the expected vulnerability of affected taxa to future warm-water disturbances.

\section{MATERIALS AND METHODS}

Study sites. Coral bleaching and community structure were investigated at representative shallow coral reef sites $(<15 \mathrm{~m}$ deep) in the western Indian Ocean (McClanahan et al. 2007). Most study sites were shallow lagoon and reef edge sites ( $<3 \mathrm{~m}$ above datum). Surveys in western Réunion included reef slope sites at $10 \mathrm{~m}$ depth, while a few sites in northern South Africa and central Mozambique were sampled in areas where rock formations and living coral were only found below $10 \mathrm{~m}$. However, depth had little effect on the trends we found (McClanahan 2007). Study sites covered $\sim 35^{\circ}$ latitude and $\sim 52^{\circ}$ longitude, representing 8 countries (southern Kenya, Tanzania, central and southern Mozambique, northern South Africa, northeast Madagascar, western Réunion [France], the granitic islands of the Seychelles [henceforth 'the Seychelles'] and the central atolls of the Maldives) and were investigated by 12 marine scientists during the peak of the warm season in 2005. This study along with studies in Kenya in 1998 (McClanahan et al. 2001), Mauritius in 2004 (McClanahan et al. 2005a) and observations in northeast Madagascar in 1998 (T. R. McClanahan unpubl. data) produced a database of responses to warm water for 37675 coral colonies, 48 taxa, and 91 reef sites, of which 71 sites were surveyed in 2005 (McClanahan et al. 2007). In order to achieve a broad and recent view of the responses of corals and the state of these reefs, we combined these data sources for a number of the analyses.

Sampling and calculation of bleaching response. We used a single, simple, and cost-effective system for monitoring bleaching, based on haphazardly selecting coral colonies and classifying them into 7 categories of coral bleaching, which allows scaling of the bleaching response by taxon and site (Gleason 1993, Edmunds et al. 2003, McClanahan 2004, Siebeck et al. 2006). The original field method was developed by Gleason (1993), modified by McClanahan et al. (2001), tested between regions (McClanahan et al. 2004), and a similar method has been tested for comparison between observers (Siebeck et al. 2006).

Taxa were identified to genus level, except for Porites, for which massive and branching forms were distinguished, and the sub-genus Synarea was treated as a separate taxon. Investigators undertook the same set of bleaching, coral diversity, and community measurements close to peaks in the DHWs (McClanahan et al. 2007). The data allow for taxon- and site-specific estimates of bleaching intensity. Further, based on the abundance of taxa at each site, and their response at all sites and times combined, a bleaching susceptibility index of the coral community was produced for each site (McClanahan 2004, McClanahan et al. 2007).

Field observations were made in shallow $(<3 \mathrm{~m})$ and deeper $(>3 \mathrm{~m}$ ) sites by snorkeling and SCUBA diving. Observers moved in haphazardly chosen directions and distances and periodically or haphazardly selected areas. All coral colonies within about $2 \mathrm{~m}$ radius were identified to the genus, counted, and assigned into 7 categories of bleaching intensity: $\mathrm{c} 1=$ normal and $\mathrm{c} 2=$ pale live coral, $\mathrm{c} 3=0-20 \%, \mathrm{c} 4=20-50 \%, \mathrm{c} 5=$ $50-80 \%$, c6 $=80-100 \%$ of the live coral surface area fully bleached, and c7 = recently dead (McClanahan 2004). This haphazard sampling of $2 \mathrm{~m}$ radius was repeated many times at sites for $\sim 40$ minutes. Each site included between 47 and 1096 colonies with a mean sample size of $380 \pm 167$ (SD) colonies per site. The total number of colonies sampled at a site was the basis of replication used in the statistical analyses. The percentage of individuals per taxon in each category was determined and the bleaching response (BR) for a site 
was calculated as a weighted average, and normalized according to the following formula:

$\mathrm{BR}=(0 \mathrm{c} 1+1 \mathrm{c} 2+2 \mathrm{c} 3+3 \mathrm{c} 4+4 \mathrm{c} 5+5 \mathrm{c} 6+6 \mathrm{c} 7) / 6$

Summing all colonies in each category and applying the above formula gave the site-specific BR. Additionally, the taxon-specific BR was determined by calculating the mean BR based on all sites where the taxon was recorded. Taking this mean taxon-specific BR, multiplying it by the taxon's relative density, summing for all taxa at each site, and scaling to 100 determined the site-specific bleaching susceptibility measure (McClanahan et al. 2007). Some sites that were very close to each other were pooled and mean values of the relative abundances and bleaching responses were used in subsequent analysis of community structure and susceptibility (McClanahan et al. 2007).

Data analyses. Sites were subjected to correlationbased Ward's hierarchical cluster analysis (Statistica) in order to assess relationships in community structure among reefs. Relative abundance of corals in the cluster groupings was used in a Correspondence Analysis of cluster group and taxon in order to distinguish the taxa contributing the most to the classification. Sites were pooled into cluster groups and the diversity, relative abundance, mean bleaching response and susceptibility for each cluster were calculated and tested for significance based on a general linear model ANOVA and Tukey-Kramer test of Honestly Significant Differences (Sall et al. 2001).

Estimates of diversity were based on the rarefaction method (Hurlbert 1971, McAleece et al. 1997). This method was chosen because of non-uniform sampling of the numbers of coral colonies and area. The rarefaction method back-calculates number of species in order to account for such differences in the number of individuals surveyed. Expected number of genera (richness) can thus be compared among locations for a sample size in common. Other conventionally used diversity indices were also calculated for comparison: number of taxa, Hill's numbers (N1 and N2), ShannonWiener $\left(H^{\prime}\right)$ and evenness (N2/N1) (Hill 1973).

To further test differences in biodiversity among clusters, we used a technique that takes into account species taxonomic relatedness and also accounts for variable sample sizes between locations. For each cluster we calculated average taxonomic distinctness (AvTD; degree to which species in a sample are related taxonomically to each other), measuring the average path length between every pair of genera through a taxonomic tree (Clarke \& Warwick 1998) and variation in taxonomic distinctness (VarTD: evenness to which the taxa are spread across the tree; Clarke \& Warwick 2001) of coral assemblages using taxonomic aggregation files constructed following Veron (2000). Funnel plots were constructed for both variables with expected mean and $95 \%$ confidence limits constructed from a simulation distribution using random subsets of the master taxonomy list. Any departure from expected values could thus be identified, low AvTD and low to normal VarTD indicating taxonomically degraded locations (Clarke \& Warwick 2001). Taxonomic distinctness is based on evolutionary relatedness and is distinct from, but sometimes related to, other measures of diversity, as found for Indian Ocean algae (Price et al. 2006).

The relationship between the relative abundance of the 10 most abundant coral genera and the DHWs that the sites experienced in 1998 was investigated with regression analysis. DHWs are defined as the cumulative degrees of temperature for the weeks that a temperature is $\geq 1^{\circ} \mathrm{C}$ above the mean temperature of the climatologically warmest month for a specific site; it is often used to predict bleaching (Liu et al. 2005, McClanahan et al. 2007) and is posted by NOAA (http://coralreefwatch.noaa.gov/satellite). Additionally, DHWs were calculated from SST data provided in the JCOMM web site (http://iri.columbia.edu/climate/ monitoring/ipb/), which uses satellite and in situ measurements presented in $1 \times 1^{\circ}$ latitude-longitude squares (Reynolds et al. 2005). McClanahan et al. (2007) investigated the relationship between (1) bleaching response, bleaching susceptibility, depth, latitude, and coral community composition and (2) NOAA and JCOMM DHWs from 1998 and 2005; the JCOMM DHWs gave a better fit. The cumulative positive anomalies from the mean summer maximum SST climatology (mean climatology of the 3 warmest months; Barton \& Casey 2005) were used for the nearest square for each location in calculating DHWs from the JCOMM data. The relationship between the BR of the 10 most dominant taxa and DHWs in 1998 and 2005 was also investigated with regression analysis. Acropora was one of the taxa most affected by the 1998 bleaching throughout the Indian Ocean and one of the dominant genera before this event. Change in relative abundance of the 9 other taxa in comparison to that of Acropora may indicate change in the degree of competitive dominance following a major disturbance that affects a superior competitor (Baird \& Hughes 2000) and was analyzed with regression analysis.

Extinction estimates are usually based on measures of vulnerability, sparseness, and rareness of the vulnerable populations (IUCN 1999). We made an estimate of the relative susceptibility to extinction (RE) of the taxa based on their bleaching response (BR), abundance or number of colonies (NC), and commonness or number of reef sites where a taxon was found (NR). Values were normalized ( 0 to 1 ) using the taxa (i) with the most extreme value (max.) for each measure such that the formula is an estimate of extinction suscepti- 
bility relative to the most bleached $\left(\mathrm{BR}_{\max }=\right.$ Alveopora $)$, most abundant $\left(\mathrm{NC}_{\max }=\right.$ Acropora $)$, and most common $\left(\mathrm{NR}_{\max }=\right.$ Acropora $)$ taxa. The formula is the logarithm of average of these 2 quotients and calculated as:

$\mathrm{RE}_{i}=\frac{\log _{10}\left(\frac{\mathrm{BR}_{i} / \mathrm{BR}_{\max }}{\mathrm{NC}_{i} / \mathrm{NC}_{\max }}\right)+\log _{10}\left(\frac{\mathrm{BR}_{i} / \mathrm{BR}_{\max }}{\mathrm{NR}_{i} / \mathrm{NR}_{\max }}\right)}{2}$

We also plotted the BR as a function of the abundance and commonness of the taxa and tested for relationships using regression analysis.

\section{RESULTS}

\section{Community structure and diversity}

Eighteen taxa had overall mean abundance $\geq 1 \%$ and composed $92 \%$ of the community (Table 1). The 10 most abundant taxa comprised $75 \%$, and the first 4 comprised $\sim 50 \%$ of the relative abundance. Acropora was the most dominant genus, followed by massive Porites and Pocillopora. Analysis of the community structure data indicates distinct patterns in the community composition with 8 clusters that fall into 3 main categories; northern South Africa/southern and central Mozambique, the central atolls of the Maldives, and the central and southern tropical western Indian Ocean (Figs. 1 \& 2). Northern South Africa/southern Mozambique and central Mozambique (Clusters 1 and 2) are typified mainly by bleaching-susceptible taxa (Table 1), including Acropora, Pocillopora, Montipora, and Acan- thastrea, moderate abundance of various faviids and an absence of a number of taxa found elsewhere, including Millepora, Pavona, and Synarea. Cluster 2 is similar to Cluster 1 but has high Stylophora abundance. The central atolls of the Maldives (Cluster 3) are dominated by massive Porites, some Pavona, both with moderate to low bleaching susceptibility, while other taxa are present but sparsely distributed. Clusters 4 to 8 are similar and distinguished by their unique subdominants. Cluster 4 includes shallow reef flat communities in western Réunion that are dominated by Acropora, Montipora, and Millepora. Reef slope sites in Réunion, shallow sites in the Seychelles, and marine protected areas (MPAs) of southern Kenya in 2005 are found in Cluster 5 and have high dominance of Pocillopora and massive Porites. Cluster 6 includes reefs scattered throughout this central and southern belt that are dominated by Acropora and massive Porites but are characterized by high subdominance of Montipora, Galaxea, Fungia, and Pocillopora. Cluster 7 is composed of heavily fished reefs in southern Kenya that have high dominance of branching Porites, followed by massive Porites, Galaxea, Favia, Pavona, and Stylophora. Central and northern Tanzania and Kenya's most southern reefs are in Cluster 8 and have a high abundance of the subdominants Synarea, Fungia, Galaxea, and massive Porites. Relationships between the relative abundance of Acropora and the other dominant genera indicate only 2 statistically significant relationships, the strongest being a negative relationship with massive Porites $\left(\mathrm{r}^{2}=0.31\right)$ and the second being a weak positive relationship with Montipora $\left(\mathrm{r}^{2}=0.10\right)$.

Table 1. Relative percentage abundance (mean $\pm \mathrm{SE}$ ) of the 18 most abundant coral taxa in the different clusters and overall abundance. Clusters: 1 = northern South Africa, southern Mozambique (2005); 2 = central Mozambique (2005); $3=$ central atolls of the Maldives (2005); 4 = western Réunion (2005); 5 = western Réunion, granitic islands of the Seychelles, southern Kenya-Marine Protected Areas (MPAs) (2005); 6 = northeast Madagascar (1998, 2005), granitic Seychelles (2005), Mauritius (2004), Kenya (1998); 7 = southern Kenya-fished (2005); 8 = Tanzania and southernmost Kenya (2005) (see also Fig. 1). mass: massive; bran: branching

\begin{tabular}{|c|c|c|c|c|c|c|c|c|c|}
\hline Genus & Cluster 1 & Cluster 2 & Cluster 3 & Cluster 4 & Cluster 5 & Cluster 6 & Cluster 7 & Cluster 8 & Overall \\
\hline Acropora & $28.34 \pm 4.11$ & $22.76 \pm 5.34$ & $7.43 \pm 1.80$ & $42.19 \pm 8.10$ & $10.27 \pm 2.83$ & $22.74 \pm 2.03$ & $1.20 \pm 0.67$ & $17.86 \pm 2.19$ & $17.50 \pm 1.57$ \\
\hline Porites (mass) & $6.53 \pm 1.29$ & $7.99 \pm 1.23$ & $32.06 \pm 4.76$ & $4.00 \pm 1.02$ & $16.06 \pm 2.81$ & $10.67 \pm 1.40$ & $15.77 \pm 1.40$ & $10.92 \pm 3.52$ & $5 \pm 1.57$ \\
\hline Pocillopora & $8.87 \pm 1.22$ & $21.26 \pm 5.45$ & $9.43 \pm 1.70$ & $6.71 \pm 1.42$ & $20.96 \pm 4.46$ & $7.21 \pm 2.05$ & $4.47 \pm 2.52$ & $5.28 \pm 0.99$ & $10.92 \pm 1.26$ \\
\hline Montipora & $9.71 \pm 2.12$ & $10.00 \pm 2.06$ & $1.91 \pm 0.60$ & $11.31 \pm 4.25$ & $2.98 \pm 1.50$ & $9.38 \pm 2.39$ & $0.10 \pm 0.10$ & $3.59 \pm 2.36$ & $6.04 \pm 0.83$ \\
\hline Galaxea & $6.85 \pm 1.87$ & $0.79 \pm 0.43$ & $1.00 \pm 0.21$ & $0.07 \pm 0.07$ & $6.77 \pm 2.54$ & $9.11 \pm 1.56$ & $11.33 \pm 2.72$ & $11.08 \pm 3.37$ & $5.92 \pm 0.85$ \\
\hline Porites (bran) & $0.21 \pm 0.15$ & $0.00 \pm 0.00$ & $3.25 \pm 1.92$ & $4.46 \pm 3.62$ & $2.81 \pm 1.66$ & $4.36 \pm 1.17$ & $25.65 \pm 4.67$ & $3.93 \pm 2.02$ & \pm 0.94 \\
\hline Pavona & $0.00 \pm 0.00$ & $0.00 \pm 0.00$ & $13.27 \pm 3.39$ & $8.78 \pm 6.01$ & $1.97 \pm 1.07$ & $3.84 \pm 0.94$ & $7.87 \pm 2.27$ & $0.56 \pm 0.22$ & \pm 0.93 \\
\hline Favia & $7.08 \pm 0.52$ & $4.52 \pm 1.22$ & $2.33 \pm 0.41$ & $0.07 \pm$ & $3.75 \pm 1.17$ & \pm 0.74 & 1.59 & $1.34 \pm 0.38$ & .75 \\
\hline Favites & $8.86 \pm 0.43$ & $5.03 \pm 1.28$ & $3.58 \pm 0.34$ & $0.00 \pm 0.00$ & $4.81 \pm 0.97$ & $2.31 \pm 0.54$ & $1.45 \pm 0.78$ & $1.20 \pm 0.63$ & $=0.40$ \\
\hline Fungia & $1.12 \pm 0.29$ & $0.50 \pm 0.23$ & $4.09 \pm$ & 0.00 & 0.09 & 58 & 0.62 & 11.10 & .37 \\
\hline Synarea & $0.00 \pm 0.00$ & & & & & & & 11. & $3.42 \pm 0.58$ \\
\hline Stylophora & $0.80 \pm 0.58$ & $12.74 \pm 4.40$ & $0.01 \pm 0.01$ & $0.00 \pm 0.00$ & $0.49 \pm 0.31$ & $0.62 \pm 0.40$ & $5.43 \pm 3.16$ & $2.35 \pm 1.76$ & $2.60 \pm 0.80$ \\
\hline Goniastrea & $2.52 \pm 0.74$ & $2.20 \pm 0.98$ & $5.98 \pm 0.92$ & $0.00 \pm 0.00$ & $8.17 \pm 2.96$ & $1.59 \pm 0.37$ & $0.30 \pm 0.19$ & $1.44 \pm 0.49$ & $2.28 \pm 0.30$ \\
\hline Millepora & $0.00 \pm 0.00$ & $0.00 \pm 0.00$ & $0.00 \pm 0.00$ & $10.20 \pm 1.11$ & $0.99 \pm 0.39$ & $2.71 \pm 0.66$ & $3.28 \pm 2.08$ & $0.87 \pm 0.34$ & $2.23 \pm 0.70$ \\
\hline Platygyra & $2.92 \pm 0.61$ & $0.00 \pm 0.00$ & $1.97 \pm 0.66$ & $0.15 \pm 0.15$ & $3.20 \pm 1.16$ & $3.15 \pm 0.61$ & $3.82 \pm 1.07$ & $1.50 \pm 0.49$ & $1.52 \pm 0.25$ \\
\hline Echinopora & $2.17 \pm 0.51$ & $2.12 \pm 1.14$ & $0.39 \pm 0.11$ & $0.07 \pm 0.07$ & $2.06 \pm 0.75$ & $0.84 \pm 0.23$ & $1.71 \pm 1.22$ & $3.33 \pm 1.06$ & $1.51 \pm 0.34$ \\
\hline Astreopora & $3.14 \pm 0.62$ & $1.00 \pm 0.42$ & & & & & & $0.81 \pm 0.46$ & $1.34 \pm 0.24$ \\
\hline Acanthastrea & $5.35 \pm 1.08$ & $2.87 \pm 0.99$ & $0.00 \pm 0.00$ & $0.00 \pm 0.00$ & $1.91 \pm 0.99$ & $0.18 \pm 0.06$ & $0.00 \pm 0.00$ & $0.06 \pm 0.04$ & $1.19 \pm 0.29$ \\
\hline
\end{tabular}




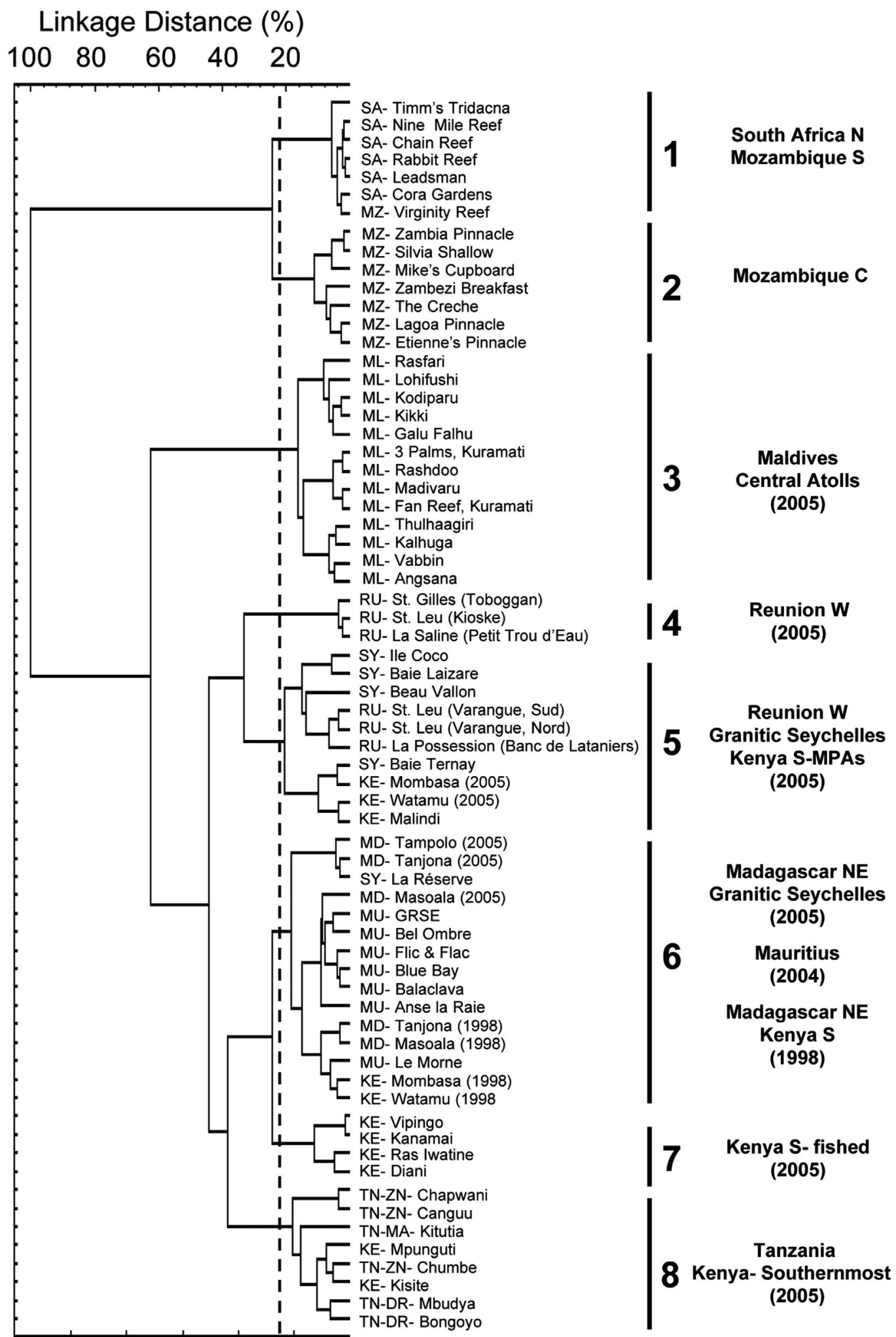

Fig. 1. Community structure of corals in the western Indian Ocean from field studies undertaken in 1998, 2004 and 2005. Dendrogram of correlation based on Ward's hierarchical cluster analysis, giving names of reefs, cluster numbers and locations (country regions) of main cluster groups. Dashed line: cut level (25\%) where the major cluster groups were identified. Year of sampling indicated for reefs that were surveyed both in 1998 and 2005, reefs with no year were all surveyed in 2005. ZN: Zanzibar Island, 


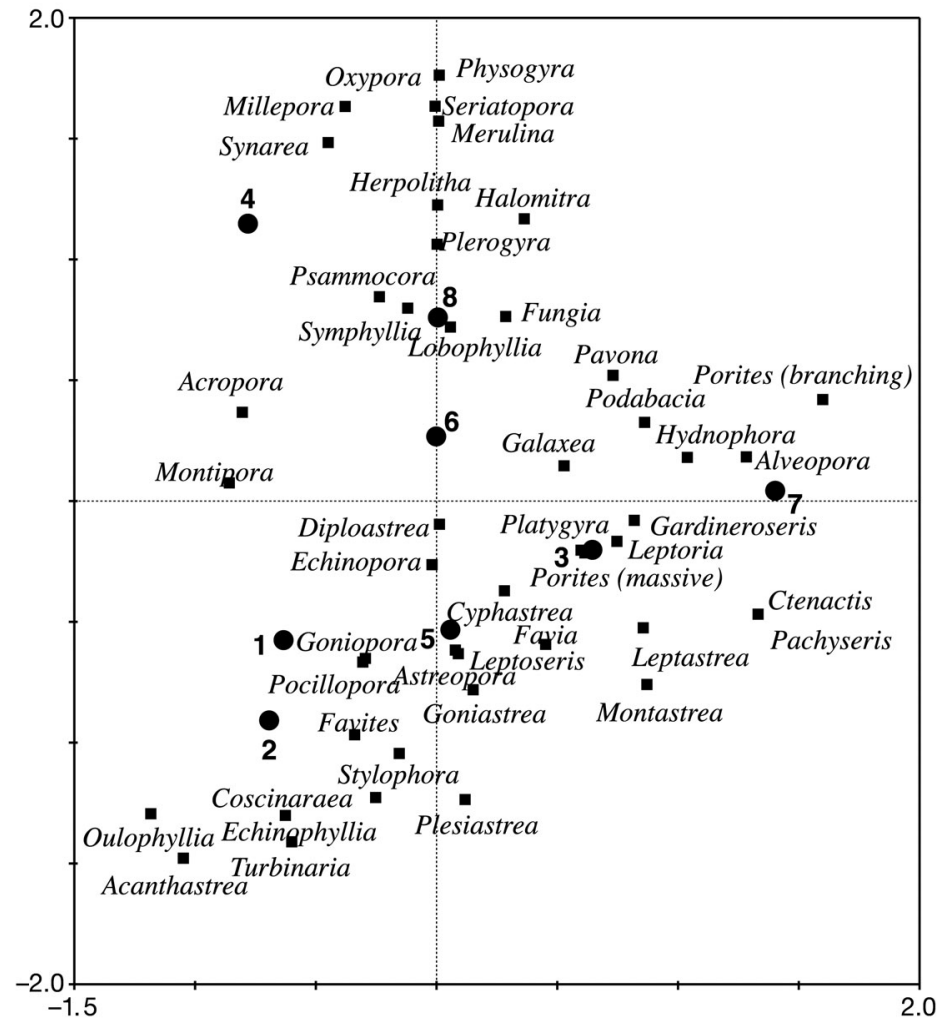

Fig. 2. Correspondence analysis plotting the 8 main clusters (•) and relative abundance of coral taxa (ロ) sampled in 1998 and 2005. Note that Ctenactis and Pachyseris are represented by the same point
Rarefaction diversity analysis indicates that the highest numbers of coral taxa are in Clusters 6 and 8 in Tanzania and southern Kenya, in Cluster 3 in the central Maldives, and a mixture of post-1998 sites in the Seychelles, Réunion, and Kenya's marine parks dominated by massive Porites and Pocillopora that form Cluster 5 (Fig. 3). Intermediate taxonomic richness was found in the northern South Africa/southern Mozambique and central Mozambique regions (Clusters 1 and 2) and Kenya's fished reefs (Cluster 7). The lowest diversity reefs were found in Réunion reef flats (Cluster 4) and were dominated by Acropora. The diversity from rarefaction method was also supported by results from other diversity measures (Table 2), where the central Maldives and Tanzania had the highest generic richness, but the Maldives was also characterized by a high dominance and low evenness. Average taxonomic distinctness identified the central Maldives (Cluster 3) to be below the confidence intervals of distinctness for the number of genera found in these sites (Fig. 4).

\section{Susceptibility to extinction}

The occurrence of genera (number of sites) increased logarithmically as a function of the number of individual colonies or solitary corals sampled (Fig. 5A). Maximum number of sites was reached at $\sim 1500$ colonies and there was a very low increase beyond this value. The bleaching response of the taxa was weakly but positively associated with their occurrence, or number of sites (Fig. 5B). Acropora and Montipora were both common and had high BRs whereas Pavona, Galaxea, Echinopora, and Fungia also had high occurrences but low BRs. The relationship showed considerable spread and many taxa were outliers from the relationship at the $95 \%$ confidence interval. For example, Alveopora and Stylophora had the highest BR, yet were only moderately common. Conversely, Gyrosmilia, Oxypora, Pachyseris, Physogyra, Plerogyra, and Plesiastrea were uncommon but had high BR. The combination of relative rarity and high BR made these taxa the most extinction-susceptible (Table 3). Other uncommon taxa such as Ctenactis, Diploastrea, Halomitra, Herpolitha, Leptoseris, Merulina, Montastrea, Oulophyllia, and Podabacia had low or no BRs.
Fig. 3. Numbers of coral genera as a function of sampling based on the rarefaction analysis where the analysis was performed by pooling sites by country and year of sampling. Rarefaction allows projection back from counts of total individuals to estimate how many genera (ESn) would have been 'expected' had we observed a smaller number of individuals. This allows counts of differing sample size to be compared. The more diverse the community is, the steeper and more elevated the rarefaction curve 
Table 2. Diversity of coral taxa (mean $\pm \mathrm{SE}$ ) in the 8 main clusters (see Table 1, Fig. 1 for cluster location)

\begin{tabular}{|c|c|c|c|c|c|}
\hline Cluster & $\begin{array}{c}\text { No. } \\
\text { of taxa }\end{array}$ & (Shannon's $\left.H^{\prime}\right)$ & $\begin{array}{c}\text { - Diversity } \\
\left.\text { (Hill's } \mathrm{N}_{1}\right)\end{array}$ & $\left(\right.$ Hill's N ${ }_{2}$ ) & $\begin{array}{c}\text { Evenness } \\
\left(\mathrm{N}_{2} / \mathrm{N}_{1}\right)\end{array}$ \\
\hline 1 & $19.86 \pm 1.18$ & $2.35 \pm 0.10$ & $10.80 \pm 1.03$ & $7.69 \pm 0.96$ & $0.70 \pm 0.03$ \\
\hline 2 & $12.86 \pm 0.86$ & $2.00 \pm 0.13$ & $7.75 \pm 0.95$ & $6.13 \pm 0.94$ & $0.77 \pm 0.04$ \\
\hline 3 & $22.62 \pm 0.95$ & $2.15 \pm 0.08$ & $8.95 \pm 0.77$ & $5.59 \pm 0.61$ & $0.61 \pm 0.02$ \\
\hline 4 & $10.00 \pm 2.08$ & $1.73 \pm 0.16$ & $5.81 \pm 0.87$ & $4.34 \pm 0.88$ & $0.73 \pm 0.05$ \\
\hline 5 & $19.36 \pm 1.06$ & $2.17 \pm 0.07$ & $8.94 \pm 0.60$ & $6.34 \pm 0.44$ & $0.71 \pm 0.02$ \\
\hline 6 & $21.62 \pm 0.96$ & $2.36 \pm 0.05$ & $10.71 \pm 0.49$ & $7.88 \pm 0.46$ & $0.73 \pm 0.02$ \\
\hline 7 & $19.50 \pm 1.55$ & $2.23 \pm 0.12$ & $9.54 \pm 1.10$ & $7.03 \pm 0.72$ & $0.74 \pm 0.03$ \\
\hline 8 & $22.25 \pm 1.96$ & $2.27 \pm 0.14$ & $10.31 \pm 1.27$ & $7.29 \pm 0.90$ & $0.71 \pm 0.02$ \\
\hline
\end{tabular}
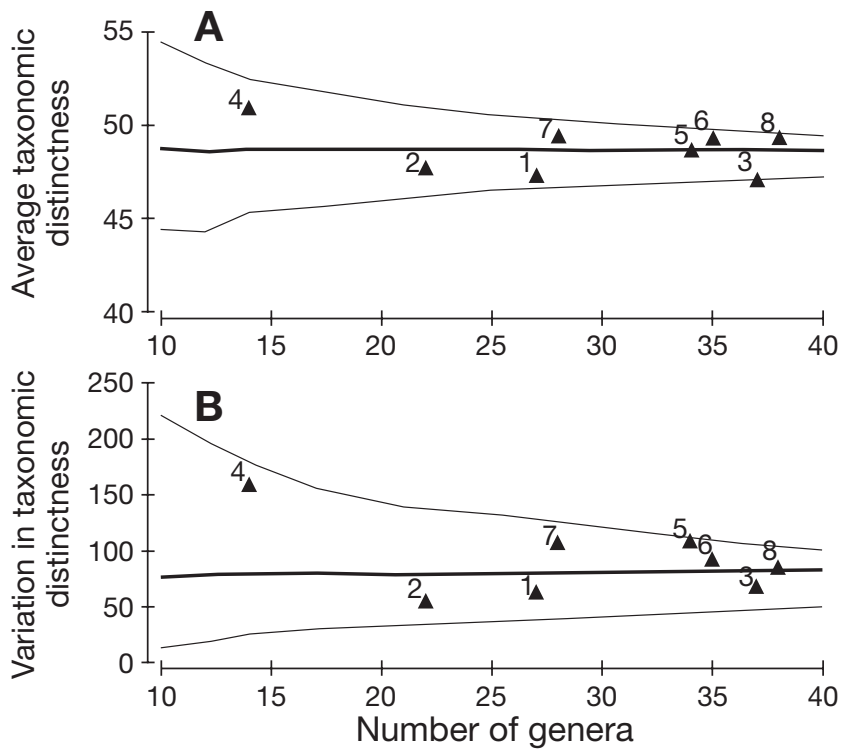

Fig. 4. (A) Average and (B) variation in taxonomic distinctness in coral generic diversity in the Indian Ocean. Diversity is analyzed based on average number of genera of the 8 major

clusters. Thin lines indicate $95 \%$ confidence intervals

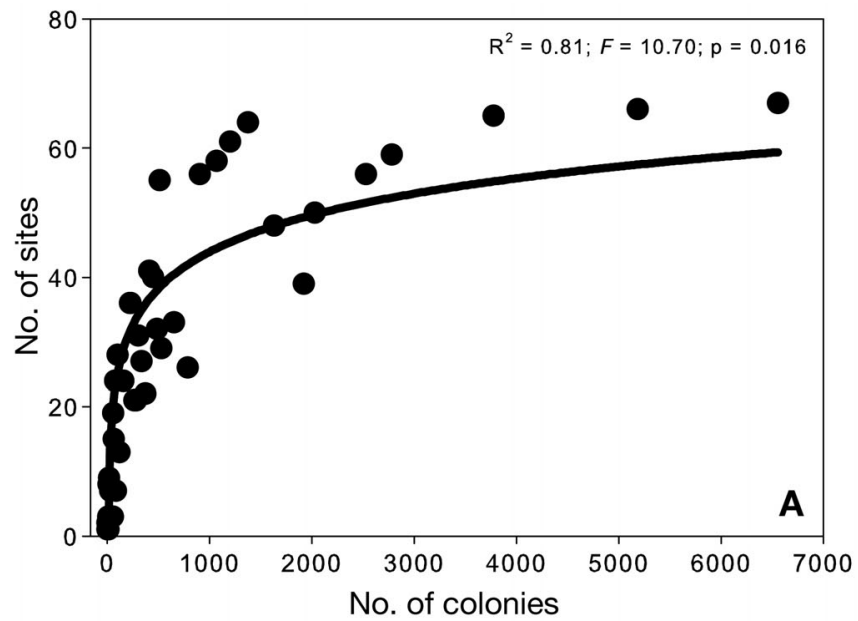

\section{Relationships to temperature}

The relationship between relative abundance of the dominant taxa of corals in the 8 clusters and DHW in 1998 indicates that the relative abundance of Acropora and Montipora decreased while massive Porites increased significantly (Fig. 6). Tests of significance found that the BR during the 2005 anomaly was highest in Clusters 2 and 6 and lowest in Clusters 7 and 8 (p<0.05) (Table 4). Sitespecific susceptibility of taxa to bleaching was higher in Cluster 2 than in Clusters 3 and 7 ( $p<0.05)$. The BR of 6 of the dominant taxa and all taxa combined increased as a function of DHWs in 2005 with Acropora and branching Porites showing the highest and Fungia the lowest responses (Fig. 7). For these same dominant taxa, with the exception of Fungia, Galaxea and branching Porites, and for all taxa combined their BR in 2005 declined as a function of the previous DHWs in 1998 in each site.

\section{DISCUSSION}

This study provides a snapshot of western Indian Ocean coral communities and their response to a warm-water anomaly in 2005, and indirectly of the community level effects of the 1998 bleaching event. The 2 bleaching events affected much of the western Indian Ocean, but the 1998 event was stronger in the north and the 2005 event was stronger in the south (McClanahan et al. 2007). This regional variation is notable in both the bleaching responses and the community structure, as reflected in relationships between

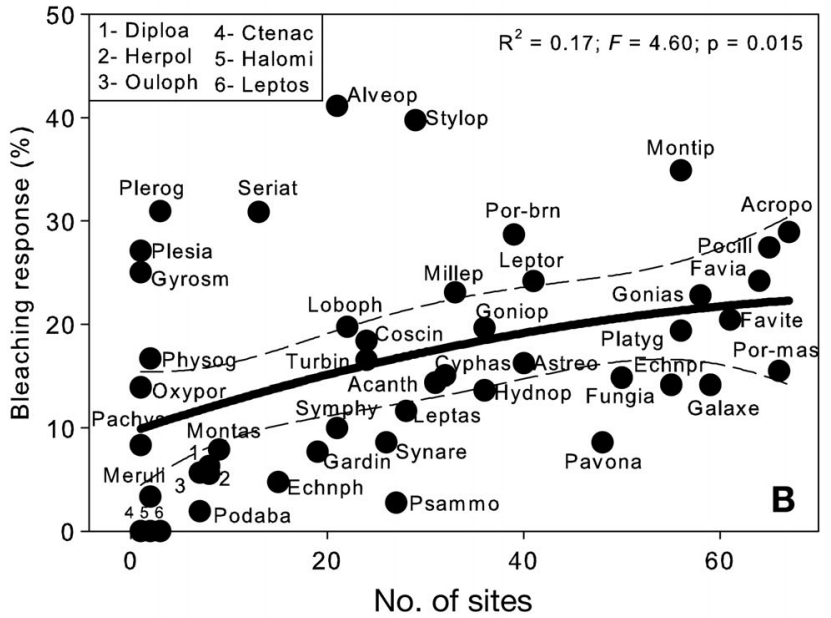

Fig. 5. Bleaching response and the abundance and commonness of coral genera. (A) Relationship between number of sites as a function of the number of coral colonies sampled and (B) bleaching response of the taxa as a function of the number of sites where the taxa were observed. Solid line: best fit, dashed lines: $95 \%$ CI for the regression. Codes of taxa given in Table 3 
Table 3. Relative extinction risk of the coral genera based on their bleaching response, abundance, commonness, and the average of both measures. Extinction risk (ER) was calculated as the average of the ranked relative bleaching response (BR) by the number of colonies (NC) and the number of reefs (NR). ER was calculated relative to the taxon with the highest BR (Alveopora), NC and NR (Acropora) (see 'Materials and methods', Eqs. 1 \& 2). mass: massive; bran: branching

\begin{tabular}{|c|c|c|c|c|c|}
\hline Taxon & Code & $\mathrm{BR}($ mean $\pm \mathrm{SD})$ & $\mathrm{NC}$ & NR & ER \\
\hline Gyrosmilia & Gyrosm & $25.00 \pm 35.36$ & 2 & 1 & 1.00 \\
\hline Oxypora & Oxypor & 13.89 & 6 & 1 & 0.81 \\
\hline Pachyseris & Pachys & 8.33 & 2 & 1 & 0.79 \\
\hline Plesiastrea & Plesia & 27.08 & 17 & 1 & 0.79 \\
\hline Physogyra & Physog & $16.67 \pm 0.000$ & 5 & 2 & 0.77 \\
\hline Plerogyra & Plerog & $30.95 \pm 39.79$ & 56 & 3 & 0.68 \\
\hline Merulina & Meruli & $3.33 \pm 4.71$ & 7 & 2 & 0.46 \\
\hline Seriatopora & Seriat & $30.86 \pm 38.10$ & 121 & 13 & 0.46 \\
\hline Alveopora & Alveop & $41.13 \pm 33.94$ & 267 & 21 & 0.41 \\
\hline Montastrea & Montas & $7.92 \pm 20.83$ & 17 & 9 & 0.40 \\
\hline Diploastrea & Diploa & $5.56 \pm 13.61$ & 14 & 8 & 0.38 \\
\hline Oulophyllia & Ouloph & $6.29 \pm 15.62$ & 22 & 8 & 0.36 \\
\hline Turbinaria & Turbin & $16.55 \pm 24.91$ & 76 & 24 & 0.34 \\
\hline Stylophora & Stylop & $39.73 \pm 37.69$ & 530 & 29 & 0.33 \\
\hline Coscinaraea & Coscin & $18.38 \pm 19.56$ & 159 & 24 & 0.30 \\
\hline Herpolitha & Herpol & $5.66 \pm 9.41$ & 86 & 7 & 0.27 \\
\hline Gardineroseris & Gardin & $7.68 \pm 19.46$ & 59 & 19 & 0.27 \\
\hline Lobophyllia & Loboph & $19.72 \pm 21.41$ & 371 & 22 & 0.27 \\
\hline Leptastrea & Leptas & $11.60 \pm 21.25$ & 103 & 28 & 0.26 \\
\hline Goniopora & Goniop & $19.63 \pm 23.73$ & 224 & 36 & 0.26 \\
\hline Leptoria & Leptor & $24.16 \pm 26.64$ & 412 & 41 & 0.24 \\
\hline Millepora & Millep & $23.06 \pm 31.91$ & 654 & 33 & 0.23 \\
\hline Echinophyllia & Echnph & $4.76 \pm 11.52$ & 63 & 15 & 0.22 \\
\hline Hydnophora & Hydnop & $13.61 \pm 16.15$ & 228 & 36 & 0.22 \\
\hline Acanthastrea & Acanth & $14.36 \pm 12.93$ & 304 & 31 & 0.22 \\
\hline Podabacia & Podaba & $1.92 \pm 3.59$ & 28 & 7 & 0.21 \\
\hline Symphyllia & Symphy & $9.98 \pm 10.05$ & 282 & 21 & 0.20 \\
\hline Cyphastrea & Cyphas & $15.05 \pm 22.24$ & 488 & 32 & 0.19 \\
\hline Astreopora & Astreo & $16.20 \pm 14.97$ & 450 & 40 & 0.19 \\
\hline Porites (bran) & Por-brn & $28.67 \pm 33.87$ & 1924 & 39 & 0.19 \\
\hline Montipora & Montip & $34.87 \pm 28.41$ & 2530 & 56 & 0.17 \\
\hline Echinopora & Echnpr & $14.15 \pm 19.44$ & 512 & 55 & 0.16 \\
\hline Platygyra & Platyg & $19.36 \pm 18.63$ & 907 & 56 & 0.16 \\
\hline Goniastrea & Gonias & $22.79 \pm 21.49$ & 1070 & 58 & 0.16 \\
\hline Favia & Favia & $24.19 \pm 22.99$ & 1376 & 64 & 0.15 \\
\hline Favites & Favite & $20.42 \pm 18.09$ & 1203 & 61 & 0.14 \\
\hline \multicolumn{6}{|l|}{ Synarea } \\
\hline (Porites rus) & Synare & $8.58 \pm 13.89$ & 786 & 26 & 0.12 \\
\hline Pocillopora & Pocillo & $27.40 \pm 30.85$ & 3779 & 65 & 0.12 \\
\hline Acropora & Acropo & $28.90 \pm 26.22$ & 6558 & 67 & 0.11 \\
\hline Fungia & Fungia & $14.84 \pm 20.93$ & 2031 & 50 & 0.10 \\
\hline Psammocora & Psammo & $2.74 \pm 5.16$ & 336 & 27 & 0.08 \\
\hline Galaxea & Galaxe & $14.15 \pm 17.94$ & 2781 & 59 & 0.08 \\
\hline Pavona & Pavona & $8.59 \pm 17.34$ & 1631 & 48 & 0.07 \\
\hline Porites (mass) & Por-mas & $15.49 \pm 19.29$ & 5184 & 66 & 0.07 \\
\hline Ctenactis & Ctenac & 0.00 & 1 & 1 & 0.00 \\
\hline Halomitra & Halomi & $0.00 \pm 0.00$ & 10 & 3 & 0.00 \\
\hline Leptoseris & Leptos & $0.00 \pm 0.00$ & 2 & 2 & 0.00 \\
\hline
\end{tabular}
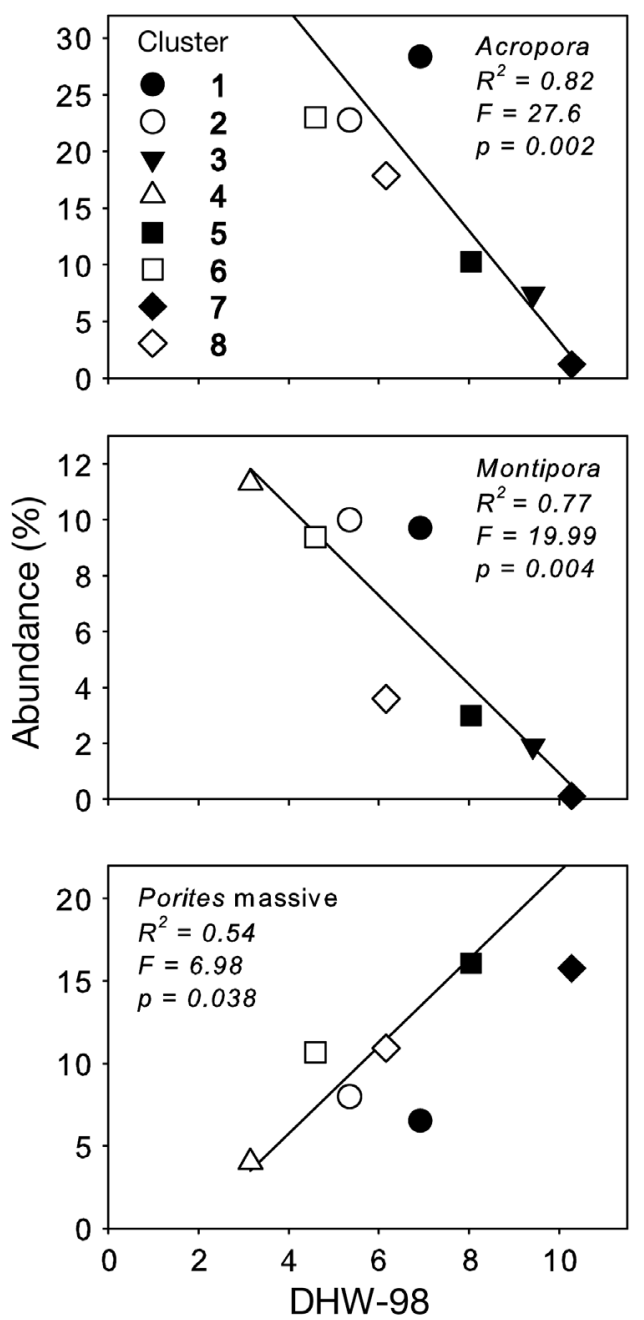

Fig. 6. Relative abundance as a function of degree heating weeks in 1998 (DHW-98) for the 3 taxa with statistically significant $(p<0.05)$ linear relationships. JCOMM DHW was used as it gave a better fit than NOAA DHW in a previous analysis. Clusters defined as in Fig. 1

Table 4. Bleaching response and susceptibility (mean \pm SE) of reefs in the 8 clusters in 2005. ANOVA summaries and TukeyKramer post hoc test of significant differences included. Cluster locations as in Table 1 and Fig. 1. Clusters with the same letter are not statistically different from each other

\begin{tabular}{|c|c|c|c|c|c|}
\hline \multirow{2}{*}{$\begin{array}{l}\text { Cluster } \\
1\end{array}$} & \multirow{2}{*}{$\begin{array}{r}\mathrm{N} \\
\\
8\end{array}$} & \multicolumn{2}{|c|}{$\begin{array}{c}\text { Bleaching response } \\
\text { (ANOVA } F=19.0 \\
\text { p }<0.0001 \text { ) }\end{array}$} & \multicolumn{2}{|c|}{$\begin{array}{c}\text { Susceptibility } \\
\text { (ANOVA } F=24.0, \\
\text { p }<0.0001 \text { ) }\end{array}$} \\
\hline & & $17.2 \pm 3.2$ & $\mathrm{a}$ & $23.04 \pm 0.58$ & $\mathrm{~b}$ \\
\hline 2 & 8 & $39.0 \pm 3.2$ & $\mathrm{~b}$ & $26.61 \pm 0.65$ & $\mathrm{a}$ \\
\hline 3 & 14 & $10.0 \pm 2.4$ & a & $17.89 \pm 0.43$ & $\mathrm{~d}$ \\
\hline 4 & 3 & $12.6 \pm 5.2$ & a & $23.68 \pm 1.01$ & abc \\
\hline 5 & 11 & $13.9 \pm 2.7$ & a & $21.34 \pm 0.49$ & $\mathrm{bc}$ \\
\hline 6 & 24 & $34.9 \pm 2.5$ & $\mathrm{~b}$ & $22.32 \pm 0.35$ & $\mathrm{~b}$ \\
\hline 7 & 4 & $4.7 \pm 4.5$ & a & $21.56 \pm 0.85$ & bc \\
\hline 8 & 10 & $5.6 \pm 2.8$ & a & $19.30 \pm 0.55$ & $\mathrm{~cd}$ \\
\hline
\end{tabular}



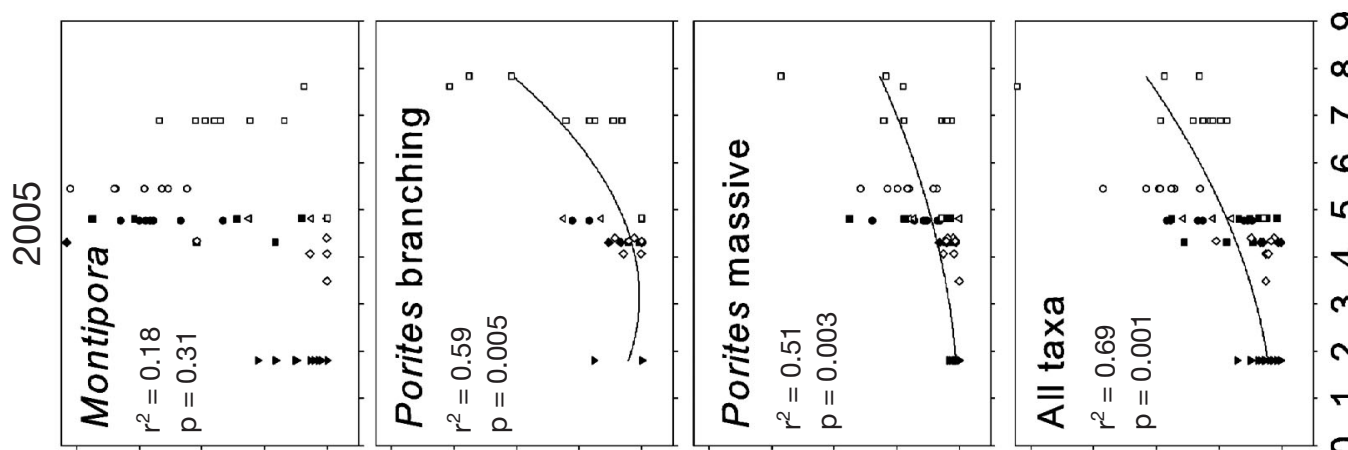

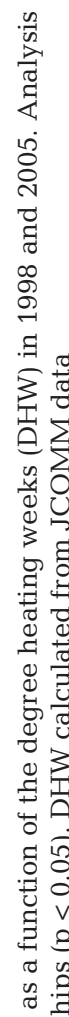
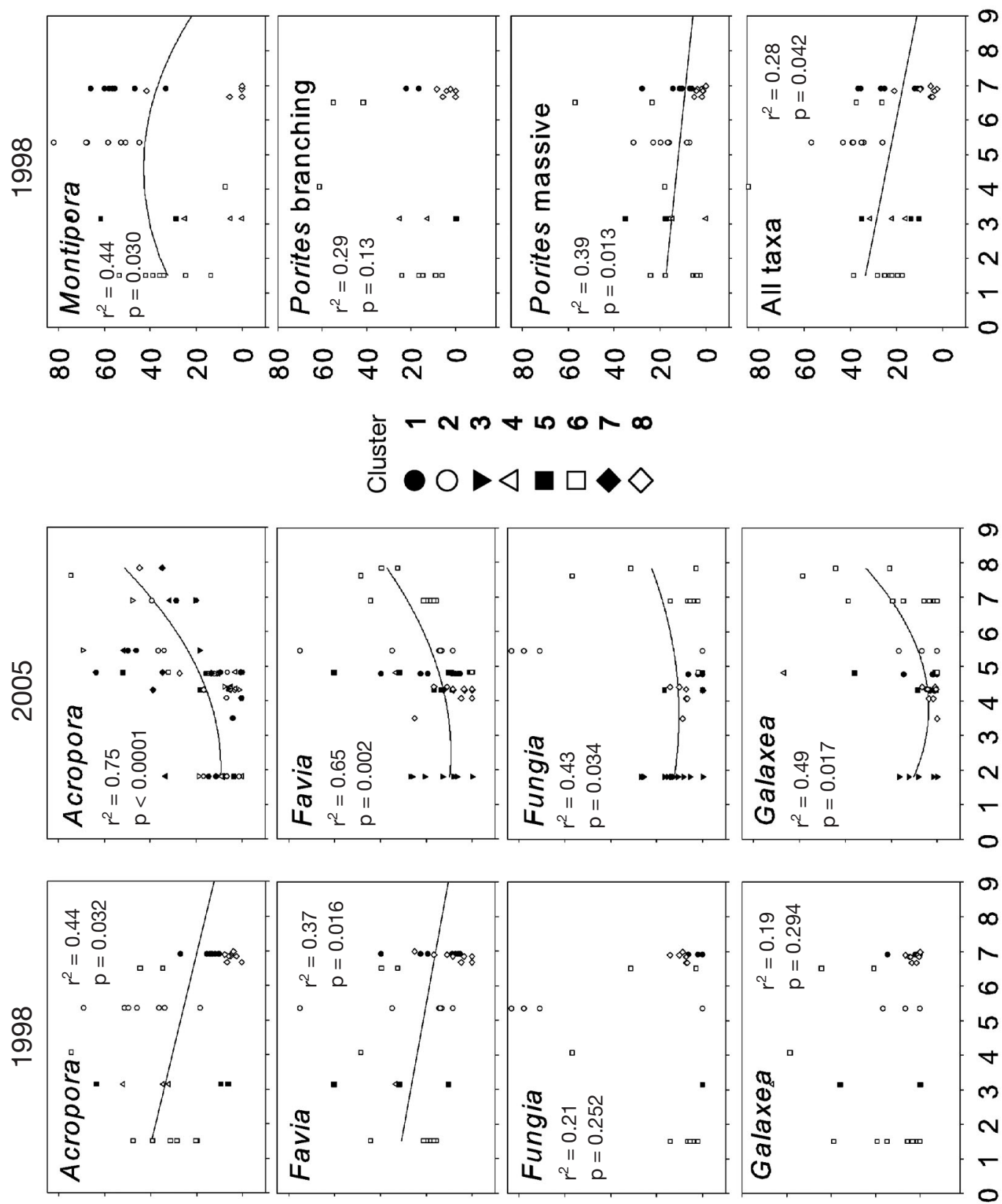

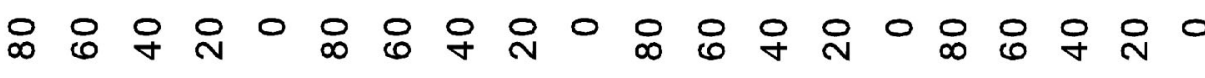
Bleaching response (\%) 
DHWs in 1998 and the abundance of the dominant coral taxa and the bleaching responses in 2005. Community structure of southern sites, with high relative cover of Acropora and Montipora, reflected communities that were not greatly altered by the 1998 event.

\section{Regional patterns}

The 2 communities that most represent reefs affected by bleaching and high levels of mortality were Cluster 3 of the central Maldives and Cluster 5, mostly in Kenya's MPAs and the Seychelles, but also outer reef slopes in western Réunion. These sites are dominated by massive Porites followed by either Pocillopora or Pavona. The sites in the central Maldives, Kenya, and granitic islands of the Seychelles had high levels of mortality (McClanahan 2000, Edwards et al. 2001, McClanahan et al. 2001, Graham et al. 2006). In some areas of the southern Maldives Acropora has recently been observed in high abundance and a number of species are reported (Pichon \& Benzoni 2007, Wallace \& Zahir 2007). Massive Porites and Pavona are moderately resistant to bleaching (Mumby et al. 2001, McClanahan 2004) and Pocillopora and Pavona appear to recruit well after bleaching events (McClanahan 2000, Loch et al. 2002, 2004). The inclusion of western Réunion reef slope sites into Cluster 5 is less clear but may reflect past disturbances from Hurricane Firinga in 1989 (Naim et al. 2000).

From southernmost Kenya to the south and east the coral communities are more representative of reefs that have experienced less mortality through bleaching, having moderate to high dominance by Acropora and other subdominant taxa that are less resistant to bleaching. Clusters 1 and 2 in South Africa and southern/central Mozambique represent 2 unique faunas in that they have some of the same dominant taxa as other reefs in the region, but have high values for some unusual subdominants, such as Acanthastrea and other faviids. They also lack (or have very low abundance of) taxa such as Millepora, Pavona, and Synarea that are more common in reefs to the north. The belt from Tanzania via Madagascar to Mauritius contains the most typical tropical coral communities for this region. It is characterized by high dominance of bleaching-sensitive taxa such as Acropora and Montipora, and the differences that distinguish the communities are in the abundance of the subdominants, including branching Porites, Fungia, Galaxea, massive Porites, Pocillopora and Synarea. Our data suggest that the higher cover of Acropora and Montipora indicates weaker effects of bleaching and less mortality in these reefs, as the relative abundance of these 2 taxa are found largely in direct proportion to the 1998 DHWs.
Cluster 7, dominated by branching Porites in Kenya's heavily fished reefs, is somewhat paradoxical, as this taxon was shown to be very sensitive to warm-water anomalies in one of Kenya's parks (McClanahan et al. 2001) and to predation by fishes (McClanahan et al. 2005b). Furthermore, it has not recovered well after the 1998 event in Kenya's MPAs (T. R. McClanahan unpubl. data). It is possible that it has greater acclimation or adaptation potential to warm water than recognized in the original site-specific study, and responds well to disturbances under different fishing or grazing conditions. Research into these and other possibilities will be needed to better understand the unusual response of this taxon.

It should be recognized that these data are relative abundances based on numbers of colonies and do not include estimates of colony size or absolute cover, and cannot be used to estimate recovery as measured by cover or population density per unit area of space. This sets limits to the usefulness of the study for determining recovery of ecological function, apart from the use of an expected community structure as a surrogate for recovery. Studies of coral cover in Kenya and the Maldives using benthic line transects suggest that the absolute cover of corals has increased on these reefs since 1998, albeit slowly (McClanahan 2000, McClanahan et al. 2005b, unpubl. data). However, there has been less recovery in the Seychelles reefs studied (Graham et al. 2006). Consequently, reefs are expected to change their taxonomic composition in response to past temperature anomalies and other disturbances (Berumen \& Pratchett 2006, McClanahan et al. 2007), while others are expected to lose coral cover and its function in the benthic community in response to rapidly warming climate (Gardner et al. 2003, Hughes et al. 2003, Sheppard 2003).

The findings from the atolls of the central Maldives indicate that, despite a very large change in the dominant taxa and community structure of these reefs (McClanahan 2000), they can maintain high numbers of taxa. Prior studies of coral biodiversity in the central Indian Ocean islands (the Maldives, Chagos, and Seychelles) indicated that reefs in this region were the center of coral biodiversity in the Indian Ocean, although East African reefs were probably considerably under-sampled at the times of these taxonomic compilations (Rosen 1971, Sheppard 1998). Nonetheless, the average taxonomic distinctness analysis identified the central Maldives as more taxonomically depauperate in terms of evolutionary relationships than expected for their level of richness. In contrast, the granitic islands of the Seychelles and Kenyan sites had high expected values for distinctness, but with lower numbers of taxa by the rarefaction method. There are no comparable data from the Seychelles sites prior to 1998, which makes it 
difficult to quantify changes. However, given that the number of taxa reported for the Seychelles in this study is lower than for the Maldives and there has been poor recovery, it seems reasonable to assume that there has been some loss of taxa.

\section{Management implications}

The findings of the study suggest a number of management priorities for sites and taxa in the region. First, southernmost Kenya and Tanzanian reefs stand out because of their high diversity and moderate bleaching effects, resulting in a community structure that still reflects the expected dominance of branching, solitary, and encrusting taxa. Tanzanian and southern Indian Ocean sites that have escaped catastrophic damage are a high priority for increased management in order to reduce synergistic stresses to corals (Moothien-Pillay et al. 2002, McClanahan et al. 2005a). Analysis of mortality after 1998 in this region indicates that high temperature variation in this region may provide some acclimation or adaptation potential, and thus resistance to warmer temperature expected under current climate change scenarios (McClanahan et al. in press).

Taxa with high bleaching responses and low occurrence are also taxa of special concern, as their rarity and susceptibility should increase the chances of their regional extirpation. Extinction in marine organisms is uncommon and difficult to predict (Vermeij 1993) and our estimate depends greatly on a number of assumptions, primarily that bleaching susceptibility is proportional to mortality, that the genus reflects the responses for the species, and that low abundance or occurrence on reefs increases extinction probabilities. These assumptions can all be challenged by past studies (Vermeij 1993, Baker et al. 2004, McClanahan 2004). An additional problem is under-sampling of rare taxa, which is unavoidable by this and most sampling methods, and this could influence estimates of bleaching responses that might be due to site-specific variables. A compilation of common genera responses suggested that while most corals that bleach do die in response to warm-water anomalies, there are also some taxa that bleach but survive (e.g. Astreopora, Favia, Favites, Goniopora and Leptoria), and others that do not bleach but die in moderate numbers (e.g. Cyphastrea and Millepora) (McClanahan 2004). Those taxa that bleach and survive are of less concern, but genera such as Cyphastrea and Millepora are of special concern, as they may often die without significant bleaching. The bleaching response of Millepora appears to vary with region (authors' pers. obs.), and a few rare species of Millepora were reported to have gone extinct or nearly extinct in the eastern Pacific during the 1983 and 1998 bleaching events (Glynn \& Feingold 1992, Glynn \& Ault 2000).

The analysis presented here provides some information for identifying taxa at risk that might benefit from captive or other forms of management. The assumption that genus-level measures reflect species responses is not critical, because 5 of the 6 taxa identified as predicted to have a high relative extinction rate are monospecific genera in this region (Gyrosmilia $=$ G. interrupta, Oxypora $=O$. lacera, Plesiastrea $=P$. versipora, Plerogyra $=P$. sinuosa and Physogyra $=P$. lichtensteini) (Veron 2000) and Pachyseris has only 2 species (P. rugosa and $P$. speciosa). Consequently, here the use of genera is sufficient to identify taxa at risk. The 2 taxa Oxypora and Pachyseris have been observed in other reefs to be bleaching tolerant (C. R. C. Sheppard pers. comm.) and their classification as extinction susceptible here may be due to small and restricted samples. Plerogyra and Physogyra are bubble corals, with big polyps, that withstand high turbidity and low light levels. Turbid conditions may protect these taxa from strong radiation and subsequent bleaching compared to shallow-water corals in non-turbid environments. In contrast, turbid conditions may create narrow environmental tolerance limits that do not favor acclimation or adaptation to anomalous conditions, as has been suggested for shallow and exposed corals (McClanahan et al. 2005a, in press). Plerogyra is in the list of the 10 most exported coral species by the aquarium trade (Wabnitz et al. 2003), which is very high for a naturally rare taxon (13900 to 60700 pieces $\mathrm{yr}^{-1}$ ). Excessive exploitation of the species could increase extinction risk, which is already suggested from the high susceptibility to bleaching and rareness. On the other hand, aquarium colonies could also be used in conservation as captive sources of 'seed' for threatened populations. The under-sampling problem may be more serious for other rare genera, some of which are monospecific (Diploastrea, Gardineroseris, and Leptoria). More effort to sample and understand their responses to temperature anomalies will be needed to determine their needs for special management.

The positive relationship between the bleaching response with abundance and commonness of corals is why many of the most bleaching-susceptible taxa have low risks of extinction in our model. Rare and siterestricted taxa were those most likely to go extinct in the eastern Pacific, associated with the 1982-83 ENSO (Glynn \& Ault 2000). Although vulnerability, declining populations, and aspects of small and sparsely distributed populations are among the main criteria for evaluating risk of extinction (IUCN 1999, Roberts et al. 2002), there are past examples of abundant and widely distributed species going extinct (Carlton et al. 1991) and reasons to believe this can happen in the marine envi- 
ronment (Hutchings 2001). It is, however, difficult to identify these taxa a priori, since all taxa included here (but one: Millepora) are scleractinians, and all have symbionts and associated life histories. Nonetheless, taxa with narrow environmental limits, restricted ranges, small population sizes, low dispersal capabilities, and slow growth are likely to be most vulnerable (Glynn 2000), and many of these attributes are identified above.

This study provides further support for the hypothesis that past bleaching episodes and associated changes in taxa and community structure provide some resistance to warm-water anomalies (Baker et al. 2004, McClanahan et al. 2007). The sites we studied in the northern Indian Ocean displayed resistance through reduced taxon-specific bleaching responses as a function of DHWs experienced in 1998, as well as resilience due to a change in the dominant taxa (McClanahan et al. 2007), with increased relative abundance of those taxa with either greater resistance to warm-water anomalies, such as massive Porites and Pavona, or disturbance-adapted life histories, such as Pocillopora. This is associated with major losses in previously dominant taxa, such as Acropora and Montipora, and possibly some losses in those taxa that are difficult to quantify but likely to include those we identified as extinctionprone. There are still a number of sites in this region that display communities and diversity that reflect less catastrophic disturbance effects, and they are among the highest regional priorities for management.

\section{Monitoring}

With the urgency to understand the threats posed by climate change, one of the main challenges in monitoring bleaching and coral communities has been in coordinating methods and the synthesis and comparison of data on an appropriately large scale. To our knowledge, our survey is the largest coordinated bleaching study yet carried out. Coordinated among 12 coral reef scientists, it covered 8 countries and 71 reef sites in one warm season. A quick and simple technique was used, which has the advantage of monitoring corals in a comparable, consistent, and standardized way in a relatively short period of time. This study also demonstrates that it is possible to investigate oceanographic anomalies and warming responses at a scale beyond the reef or country level (McClanahan et al. 2007). Such smaller-scale studies often use a wide variety of techniques, often semi-quantitative, and comparison between methods and observers is difficult. With the increased uncertainties in the global synopsis of corals and possible extinctions, our simple and cost-effective method can be used as a global protocol for assessment and monitoring of coral communities and bleaching.
Acknowledgements. The work was coordinated by the Wildlife Conservation Society and supported through grants from Western Indian Ocean Marine Science Association (WIOMSA) Marine Science for Management Program (MASMA), Leverhulme Trust, Eppley and Tiffany Foundations, and the World Bank Targeted Research Group on Coral Bleaching. We are grateful to Haji Machano Ali, Andrew Baker, Nyawira Muthiga, Kerry Sink, Hannelore Waska and the African Coelacanth Ecosystem Program for assistance with field studies.

\section{LITERATURE CITED}

Baird AH, Hughes TP (2000) Competitive dominance by tabular corals. an experimental analysis of recruitment and survival of understorey assemblages. J Exp Mar Biol Ecol 251:117-132

Baker AC, Starger CJ, McClanahan TR, Glynn PW (2004) Corals' adaptive response to climate change. Nature 430: 741

Barton AD, Casey KS (2005) Climatological context for largescale bleaching. Coral Reefs 24:536-554

Berumen ML, Pratchett MS (2006) Recovery without resilience: persistent disturbance and long-term shifts in the structure of fish and coral communities at Tiahura Reef, Moorea. Coral Reefs 25:647-653

Carlton JT, Vermeij GJ, Lindberg DR, Carlton DA, Dudley EC (1991) The first historical extinction of a marine invertebrate in an ocean basin: the demise of the eelgrass limpet Lottia alveus. Biol Bull 180:72-80

Clarke KR, Warwick RM (1998) A taxonomic distinctness index and its statistical properties. J Appl Ecol 35:523-531

Clarke KR, Warwick RM (2001) A further biodiversity index applicable to species lists: variation in taxonomic distinctness. Mar Ecol Prog Ser 216:265-278

Edmunds PJ, Gates RD, Gleason DF (2003) The tissue composition of Montastraea franksi during a natural bleaching event in the Florida Keys. Coral Reefs 22:54-62

Edwards AJ, Clark S, Zahir H, Rajasuriya A, Naseer A, Rubens J (2001) Coral bleaching and mortality on artificial and natural reefs in Maldives in 1998, sea surface temperature anomalies and initial recovery. Mar Poll Bull 42:7-15

Gardner TA, Cote IM, Gill JA, Grant A, Watkinson AR (2003) Long-term region-wide declines in Caribbean corals. Science 301:958-960

Gleason MG (1993) Effects of disturbance on coral communities: bleaching in Moorea, French Polynesia. Coral Reefs 12:193-201

Glynn PW (2000) El Niño-Southern Oscillation mass mortalities of reef corals: a model of high temperature marine extinctions? In: Insalaco E, Skelton PW, Palmer TJ (eds) Carbonate platform systems: components and interactions. Spec Pub 178. Geological Society of London, London, p 117-133

Glynn PW, Ault JS (2000) A biogeographic analysis and review of the far eastern Pacific coral reef region. Coral Reefs 19:1-23

Glynn PW, Feingold JS (1992) Hydrocoral species not extinct. Science 257:1845

Goreau T, McClanahan T, Hayes R, Strong A (2000) Conservation of coral reefs after the 1998 global bleaching event. Conserv Biol 14:5-15

Graham NAJ, Wilson SK, Jennings S, Polunin NVC, Bijoux J, Robinson J (2006) Dynamic fragility of oceanic coral reef ecosystems. Proc Natl Acad Sci USA 103:8425-8429 
Hill MO (1973) Diversity and evenness: a unifying notation and its consequences. Ecology 54:427-473

Hoegh-Guldberg O (1999) Climate change, coral bleaching and the future of the world's coral reefs. Mar Freshw Res 50:839-866

Hughes TP, Baird AH, Bellwood DR, Card M and 13 others (2003) Climate change, human impacts, and the resilience of coral reefs. Science 301:929-933

Hurlbert SH (1971) The nonconcept of species diversity: a critique and alternative parameters. Ecology 52:577-586

Hutchings JA (2001) Conservation biology of marine fishes: perceptions and caveats regarding assignment of extinction risk. Can J Fish Aquat Sci 58:108-121

IUCN (1999) IUCN Red List categories. International Union for the Conservation of Nature, London

Liu G, Strong AE, Skirving W, Arzayus LF (2005) Overview of NOAA coral reef watch program's near-real time satellite global coral bleaching monitoring activities. Proc 10th Int Coral Reef Symp, Okinawa, p 1783-1793

Loch K, Loch W, Schuhmacher H, See WR (2002) Coral recruitment and regeneration on a Maldivian reef 21 months after coral bleaching event of 1998. PSZN I: Mar Ecol 23:219-236

Loch K, Loch W, Schuhmacher H, See WR (2004) Coral recruitment and regeneration on a Maldivian reef four years after the coral bleaching event of 1998. Part 2: 2001-2002. PSZN I: Mar Ecol 25:145-154

Marshall PA, Baird AH (2000) Bleaching of corals on the Great Barrier Reef: differential susceptibilities among taxa. Coral Reefs 19:155-163

McAleece N, Lambshead PJD, Paterson GLJ, Gage JD (1997) BioDiversity Professional Statistics Package. The Natural History Museum of London and the Scottish Association for Marine Science, London

McClanahan TR (2000) Bleaching damage and recovery potential of Maldivian coral reefs. Mar Poll Bull 40: 587-597

McClanahan TR (2004) The relationship between bleaching and mortality of common corals. Mar Biol 144:1239-1245

McClanahan TR, Muthiga NA, Mangi S (2001) Coral and algal changes after the 1998 coral bleaching: interaction with reef management and herbivores on Kenyan reefs. Coral Reefs 19:380-391

McClanahan TR, Maina J, Moothien-Pillay R, Baker AC (2005a) Effects of geography, taxa, water flow, and temperature variation on coral bleaching intensity in Mauritius. Mar Ecol Prog Ser 298:131-142

McClanahan TR, Maina J, Herron-Perez P, Dusek E (2005b) Detriments to post-bleaching recovery of corals. Coral Reefs 24:230-246

McClanahan TR, Ateweberhan M, Ruiz Sebastián C, Graham NAJ, Wilson SK, Bruggemann JH, Guillaume MMM (2007) Predictability of coral bleaching from synoptic satellite and in situ temperature observations. Coral Reefs doi: 10.1007/s00338-006-0193-7

McClanahan TR, Ateweberhan M, Muhando C, Mohammed SM (in press) Climate change, spatio-temporal variation in seawater temperature effects on coral bleaching and mortality in East Africa. Ecol Monogr

Editorial responsibility: Howard Browman (Associate Editorin-Chief), Storebø, Norway
Moothien-Pillay R, Terashima H, Kawasaki H (2002) The extent and intensity of the 1998 mass bleaching event on the reefs of Mauritius, Indian Ocean. Galaxea 4: $43-52$

Mumby PJ, Chisholm JRM, Edwards AJ, Clark CD, Roark EB, Andrefouet S, Jaubert J (2001) Unprecedented bleachinginduced mortality in Porites spp. at Rangiroa Atoll, French Polynesia. Mar Biol 139:183-189

Naim O, Chabanet P, Done T, Tourrand C, Letourneur Y (2000) Regeneration of a reef flat ten years after the impact of the cyclone Firinga (Réunion, SW Indian Ocean). Proc 9th Int Coral Reef Symp, Bali 1:547-553

Pichon M, Benzoni F (2007) Taxonomic re-appraisal of zooxanthellate scleractinian corals in the Maldives Archipelago. Zootaxa 1441:21-33

Price ARG, Vincent LPA, Venkatachalam AJ, Bolton JJ, Basson PW (2006) Concordance between different measures of biodiversity in Indian Ocean macroalgae. Mar Ecol Prog Ser 319:85-91

Reynolds RW, Zhang HM, Smith TM, Gentemann CL, Wentz F (2005) Impact of in situ and additional satellite data on the accuracy of a sea-surface temperature analysis for climate. Int J Climatol 25:857-864

Roberts CM, McClean CJ, Veron JEN, Hawkins JP and 8 others (2002) Marine biodiversity hotspots and conservation priorities for tropical reefs. Science 295:280-284

Rosen BR (1971) The distribution of reef coral genera in the Indian Ocean. Symp Zool Soc Lond 28:263-299

Sall J, Lehmaan A, Creighton L (2001) JMP Start Statistics. Thomson Learning, Duxbury

Sheppard CRC (1998) Biodiversity patterns in Indian Ocean corals, and effects of taxonomic error in data. Biodivers Conserv 7:847-868

Sheppard CRC (2003) Predicted recurrences of mass coral mortality in the Indian Ocean. Nature 425:294-297

Siebeck UE, Marshall NJ, Kluter A, Hoegh-Guldberg O (2006) Monitoring coral bleaching using a colour reference card. Coral Reefs 25:453-460

van Woesik R (2000) Modelling processes that generate and maintain coral community diversity. Biodivers Conserv 9:1219-1233

Vermeij GJ (1993) Biogeography of recently extinct marine species: implications for conservation. Cons Biol 7: 391-397

Veron J (2000) Corals of the world. Australian Institute of Marine Science, Townsville

Wabnitz C, Taylor M, Green E, Razak T (2003) From ocean to aquarium. UNEP-World Conservation Monitoring Centre, Cambridge

Wallace CC, Zahir H (2007) The 'Xarifa' expedition and the atolls of the Maldives, 50 years on. Coral Reefs 26:3-5

Wilkinson C, Linden O, Cesar H, Hodgson G, Rubens J, Strong AE (1999) Ecological and socioeconomic impacts of 1998 coral mortality in the Indian Ocean: an ENSO impact and a warning of future change? Ambio 28:188-19

Wilson SK, Graham NAJ, Pratchett MS, Jones GP, Polunin NVC (2006) Multiple disturbances and the global degradation of coral reefs: Are reef fishes at risk or resilient? Global Change Biol 12:2220-2234

Submitted: December 7, 2006; Accepted: April 10, 2007 Proofs received from author(s): May 2, 2007 